\title{
General paper \\ STRENGTHENING AND MONITORING CONCRETE STRUCTURES USING GLASS FIBER COMPOSITES AND FBG SENSOR
}

\author{
Kin-Tak LAU*, Li-Min ZHOU*, Chung-Ho Woo*, \\ Kok-Cheung CHAN** and Wei JiN** \\ "Department of Mechanical Engineering, The Hong Kong Polytechnic University, \\ Hung Hom, Kowloon, Hong Kong \\ "* Department of Electrical Engineering, The Hong Kong Polytechnic University, \\ Hung Hom, Kowloon, Hong Kong
}

\begin{abstract}
The research works related to the use of fibre reinforced plastics (FRP) in civil concrete engineering application have been found increasingly only in recent years. Most of the studies were concentrated on the use of bonding FRP onto the plain rectangular beams and columnar concrete specimens under three point bending and uni-axial compression tests, respectively. The results gave a compromising solution for both strengthening and retrofitting of plain concrete samples. Unfortunately, the defection of the reinforced sample cannot be measured visibly due to the coverage of the bonding patch. To increase the efficient and precision in monitoring of the strengthened structure, Fibre-optic Bragg Grating (FBG) sensor is being introduced in embedding it into the structure to measure the internal strain under applied load. This paper presents the experimental results of cylindrical concrete specimens with and without strengthening by wrapping glass fibre composites under uni-axial compression loading. FBG sensors were pre-embedded into concrete specimens and at the interface between the reinforced laminate and concrete surface. The test results show a considerable increase in the ultimate compressive strength and confine the lateral expansion of the strengthened specimens. The strains extracted from the embedded FBG sensor compare well with that measured by the surface bonded electrical strain gauges.
\end{abstract}

Key words: Advanced composite materials, Glass fibre laminates, Fibre-optic bragg grating sensor, Concrete structure, Concrete rehabilitation

\section{INTRODUCTION}

In this decade, the maintenance of infrastructures such as bridges, dams and tunnels has become a serious problem around the world. The majority of rehabilitation work consists of repair of old deteriorating concrete structures that were damaged by ageing, corrosion of reinforced steel bar, natural calamity such as earthquake, accidental event and initial faulty design [1-2]. It has been estimated that the United States would face to pay for US $\$ 167$ billion cost for the repairs of deficient bridges and roads [3]. According to the statistical figures from the Department of Transport Report in British, the replacement value for the old and deteriorated concrete bridges is nearly $£ 10$ billion and the government spent about $£ 215$ millions for maintenance and repair of over 40,000 deteriorated concrete structures [4]. In Asia, many structural deficiencies in bridges and offshore structures come the growing need for effective means of rehabilitating these structures.

The conventional rehabilitating techniques using stitching and external bonded steel patch design did provide a promising strengthening solution in civil concrete application [5-11]. Unfortunately, the weight penalty, labour intensive and subsequent corrosion of the steel reinforcement eventually increases the overall maintenance cost in long term strategy. Therefore, this requires the development and application of new materials and technologies to prolong the structure life of defective facilities with reducing the maintenance cost (time) and improving the structure durability.

Received December 7, 1998

Accepted July 21, 1999
Over the past decades, several high-strength and light- weight fibre reinforced plastics (FRP) have been developed mainly for the aerospace and defense applications. Since 1991, the interest of using FRP in the highway structures has been increased rapidly [12-13]. Their chemical resistance to the effects of chloride attack and corrosion represents an attractive feature for structural design engineers. Recent researches and experiments related to the use of composite materials for concrete rehabilitation and repair have shown that using this method can reduce the overall maintenance cost and time, and minimise the risk of traffic interruption [14$15]$.

Glass fibre reinforced plastics (GFRP) offer an attractive alternative to steel for using as external reinforcement because of its light in weight, chemical inertness environment, low labour intensive, resistance to fatigue damage, easy to perform and cost reduction in both maintenance and replacement of the old deteriorated structures. It provides a deal of potential in strengthening concrete structure because of its high tensile strength properties, enabling it to overcome the tension weak characteristic of concrete materials. Thus, the application of this strengthening technique is becoming more and more important in extending the service life of the civil construction facilities into the 21 st century.

In addition, the structures after strengthening require the need of in-situ structural health monitoring system to reveal the mechanical behaviour under the service loading conditions. The conventional non-destructive 
inspection methods such as external bonded strain gauge measurement, dye penetrant-enhanced X-ray radiography have been used widely and accepted by the industrial application. However, they are unsuitable for the on-line monitoring purpose [16]. Therefore, the embedded strainmeasuring device is necessary to determine the full strain state inside the structures.

Fibre-optic Bragg Grating (FBG) sensors have attracted considerable interest recently for their potential application in structure monitoring, particularly in the observation of temperature and strain in composite materials [17-18]. In this technique, a refractive index grating is written into a single-mode germanium-doped optical fibre by exposing the fibre to an Ultra-violet (UV) interference signal [19]. Strain is sensed by monitoring the reflected or transmitted wavelength shift from the grating when it is subjected to strain in lengthwise direction. In-situ strain measurement by embedding FBG sensor into stress sensitive area is able to manage the health, assess damage and determine the properties of the structures. The major characteristic of using FBG sensor for the structural health monitoring is the capable of pointwise measuring strain with high resolution and accuracy [20].

In this paper, we present an effective strengthening technique of bonding GFRP on the cylindrical concrete specimen with the aid of embedding FBG sensor as a self structural health monitoring device. The results of the experimental studies on cylindrical concrete specimens strengthened by wrapping GFRP laminate externally are discussed.

\section{FIBRE-OPTIC BRAGG GRATING SENSOR}

The basic principle in measuring the strain of the fibre-core of the optical fibre is to measure the wavelength shift reflected from the grating when the fibre is subjected to the lengthwise straining. The grating of the fibre is formed using a pulsed ultraviolet source. The FBG system is composed of the broadband source, light emission device, optical spectrum analyser (OSA), coupler and FBG sensor. The whole system is illustrated schematically in Fig. 1. In the system, the light reflected from the grating sensor is returned via the coupler to the OSA and the reflected wavelength can be recorded simultaneously when the grating is strained.

The FBG being a sensor is based on the physical behaviour of refractive index of the fibre-core and the grating period (called "spatial pitch"). Both parameters are changed with the variation of mechanical strain in the fibre-grating region. The strain of the fibre can be directly obtained from the elastic equation:

$$
\varepsilon_{\mathrm{f}}=\frac{\Delta L}{L}
$$

The reflected wavelength from the grating $\left(\lambda_{\mathrm{B}}\right)$ is determined by the change of spatial pitch $(\Lambda)$ of the index modulation and the core reflective index $\left(n_{\text {eff }}\right)$

$$
\lambda_{\mathrm{B}}=2 n_{\mathrm{eff}} \Lambda \text {. }
$$

Differentiating the above equation with respect to mechanical strain $\varepsilon_{\mathrm{f}}$ yields

$$
\frac{\partial \lambda_{\mathrm{B}}}{\partial \varepsilon_{\mathrm{f}}}=2 \Lambda\left[\frac{\partial n_{\mathrm{eff}}}{\partial \varepsilon_{\mathrm{f}}}\right]+2 n_{\mathrm{eff}}\left[\frac{\partial \Lambda}{\partial \varepsilon_{\mathrm{f}}}\right]
$$

It has been approved that the sensor gives a linear strain response to the wavelength shift if the deformation of the sensor is within the elastic range [19]. Therefore, the Eq.(3) can be expressed as:

$$
\Delta \lambda_{\mathrm{B}}=K_{\varepsilon} \Delta \varepsilon_{\mathrm{f}}
$$

By integrating the Eq.(4), the relation between the wavelength and strain become

$$
\varepsilon_{\mathrm{f}}=K \lambda_{\mathrm{B}}+C_{1} .
$$

where the value of ' $K_{\varepsilon}^{\prime}$ is called the 'theoretical gauge constant'. By using the Eq.(5), the microstrain of the test specimen can be obtained straightly with the phase shift if the constants $K$ and $C_{1}$ are known.

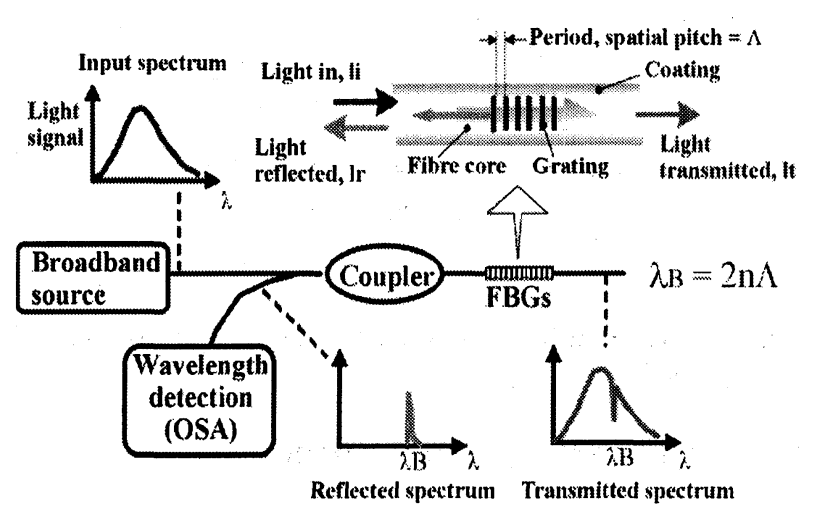

Fig.1. FBG sensor operation system.

In order to determine the value of constant $K$, a preliminary test was firstly performed. A standard steel dog-bone specimen was used in a tensile test. The schematic diagram of the tensile testing specimen is shown in Fig. 2. A FBG sensor was glued on surface of the test specimen, while the electrical strain gauge was bonded on the other surface by using epoxy adhesive. The adhesive thickness was controlled evenly by using the spring clamp cushioned by a soft rubber chip. The strain reading from the strain gauge and the reflected wavelength were recorded by using a data logger and OSA, respectively. The experimental results are shown in Figs. 3 and 4 . The results obtained from the FBG sensor give a good agreement compared with the strain gauge, which was bonded on the opposite side of the testing coupon. The constant variable $K$ is determined by fitting the curve in Fig.3. The resulted value of $K$ is $947.55 \mathrm{~nm}^{-1}$. This implies that each $947.55 \mathrm{~nm}^{-1}$ shift of 
wavelength corresponds to $1 \times 10^{-6}$ strain change. The unit of $\lambda_{\mathrm{B}}$ is in $\mathrm{nm}$. Thus, the Eq.(5) can be written as

$$
\varepsilon_{\mathrm{f}}=947.55 \lambda_{\mathrm{B}}-1473917.45
$$

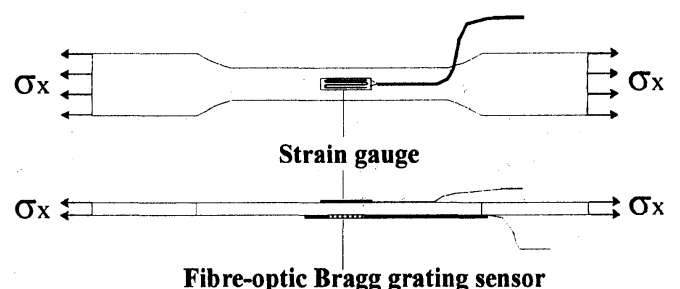

Fig.2. Tensile testing specimen for calibration test.

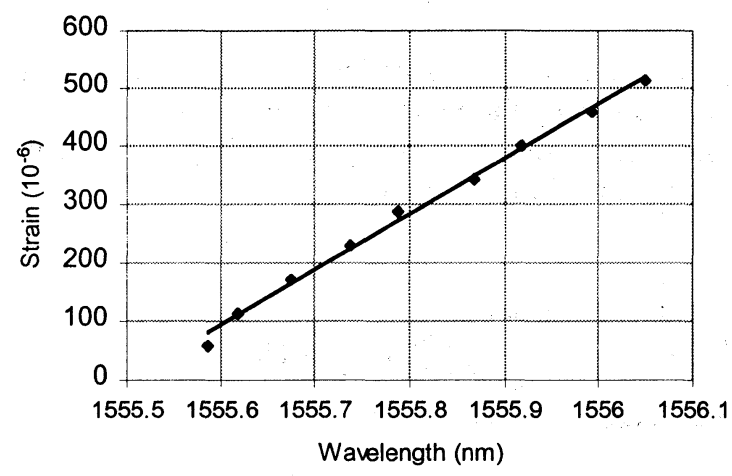

Fig.3. Wavelength-strain curve extracted from the calibration test.

\section{EXPERIMENTAL PROCEDURE}

The experimental procedure consists of examination of material properties, concrete moulding (include embedding FBG sensor into the test specimens) and mechanical property tests of cylindrical concrete specimens with and without strengthening by wrapping GFRP laminate.

The cylindrical concrete specimens were made as a laboratory size $100 \mathrm{~mm}$ in diameter and $200 \mathrm{~mm}$ in height. The mix ratio $1: 1.5: 3$ and $\mathrm{w} / \mathrm{c}$ ratio 0.5 were selected to fabricate the concrete specimen as it is a composition widely used in constructional industry. Uni-axial compression tests (ASTM C39) were then performed for both confined and plain concrete specimens. All constituents were cast into the circular steel mould and de-moulded after 24 hours. The concrete was then cured for 28 days, at $25^{\circ} \mathrm{C}$ in $100 \%$ humidity condition for the completion of hydration process. Notch was made at the middle-height of some specimens in $0.2 D$ depth $(D=$ diameter of specimen), in order to simulate the existence of a crack. All specimens were then reinforced by different number of GFRP wrappings. Three same specimens were used for each individual test. The schematic diagram of the concrete specimen with and without notch formation by wrapping GFRP laminates is shown in Fig. 5.

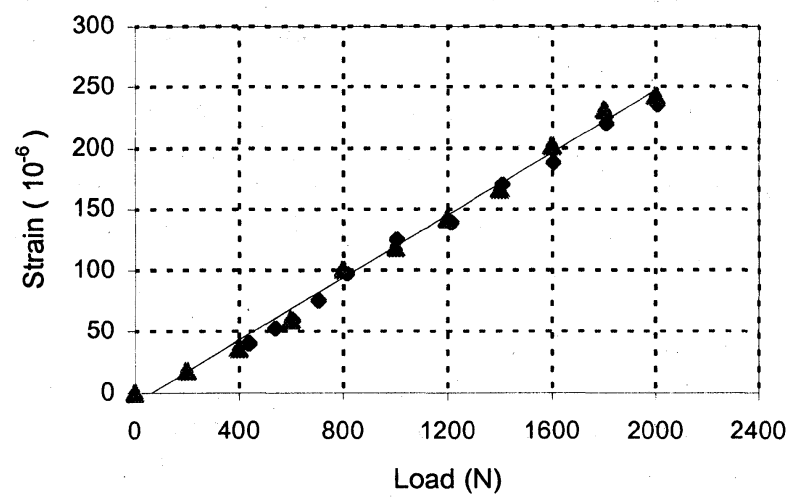

Fig.4. The load-strain curve extracted from the calibration test (diamond spot: strain gauge results; triangular spot: FBG sensor results).

E-glass $\left(0^{\circ} / 90^{\circ}\right)$ woven mat and Araldite MY750 epoxy resin were used to form the GFRP composites. The tensile and compressive strength properties of GFRP composites measured by the experiments are listed in Table 1. The tensile modulus and the Poisson's ratio were measured experimentally as $9.43 \mathrm{GPa}$ and 0.176 , respectively.

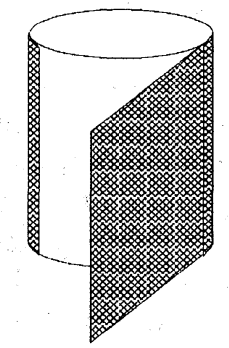

PLAIN CONCRETE SPECIMEN

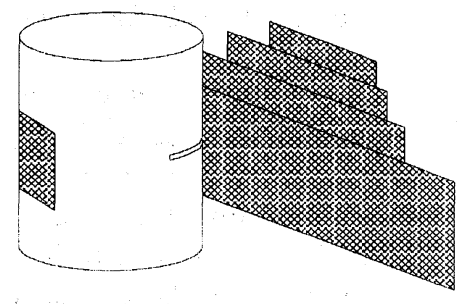

NOTCHED CONCRETE SPECIMEN

Fig.5. Schematic illustration of the plain and notched concrete specimens with wrapped GFRP laminate.

Table 1. Tensile and compressive strength test results of GFRP composite laminates.

\begin{tabular}{lllll}
\hline Description & \multicolumn{4}{c}{ No. of composite layers } \\
& 1 & 2 & 3 & 8 \\
\hline & & & & \\
Fibre volume fraction $(\%)$ & 19.9 & 26.6 & 31.2 & 29.2 \\
Tensile strength, $\sigma_{\mathrm{u}}(\mathrm{MPa})$ & 110 & 133 & 178 & 180 \\
Tensile strain, $\varepsilon_{\mathrm{u}}\left(10^{-2}\right)$ & 1.24 & 1.36 & 1.5 & 1.59 \\
Compressive strength, $\sigma_{\mathrm{cu}}(\mathrm{MPa})$ & & & & 50 \\
Compressive strain, $\varepsilon_{\mathrm{cu}}\left(10^{-2}\right)$ & & & & 0.79
\end{tabular}


FBG sensor were installed in various forms in the specimens. These include: (1) embedded into the plain concrete samples; (2) bonded at the interface between glass fibre laminate and concrete surface in parallel and perpendicular to the direction of loading; (3) embedded inside the notched concrete specimens and located in front of the notch tip. The schematic diagram of the experiment set up in strain measurement by using FBG sensor, and the test specimens with surface bonded strain gauges and embedded FGB sensor are shown in Figs.6 and 7, respectively.

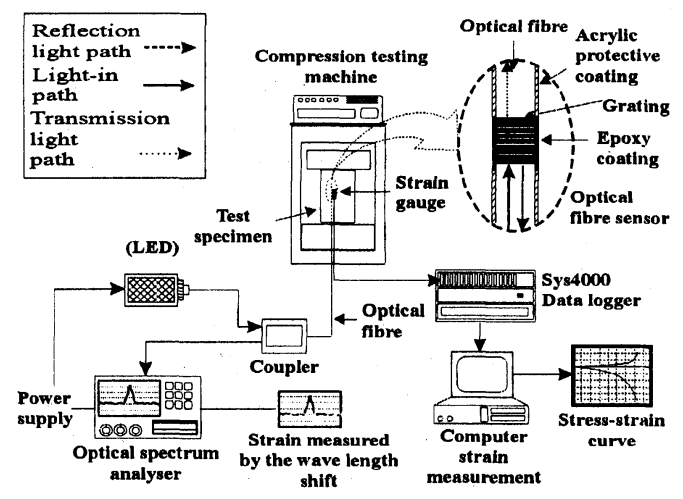

Fig.6. Schematic of the experiment set-up of cylindrical concrete specimen under uni-axial compression test.

To avoid the damage of the fibre sensor in moulding process, special design of the supporting fixture for aligning and reinforcing the sensor was introduced. Thin and tough nylon string was used to align and guide the optical fibre in line parallel to the load direction. Both ends of the sensor were sticked on the string by using epoxy adhesive. High flexile rubber tubes were used to protect the fibre at the entrance and exit locations of the specimen to minimise the risk of fibre breakage due to the formation of sharp turning angle or unexpected damage during the moulding and de-moulding processes. The schematic diagram of the optical fibre installation technique is shown in Fig.8.

Calibration of the FBG sensor was performed in the early stage. The sensors were embedded into the plain

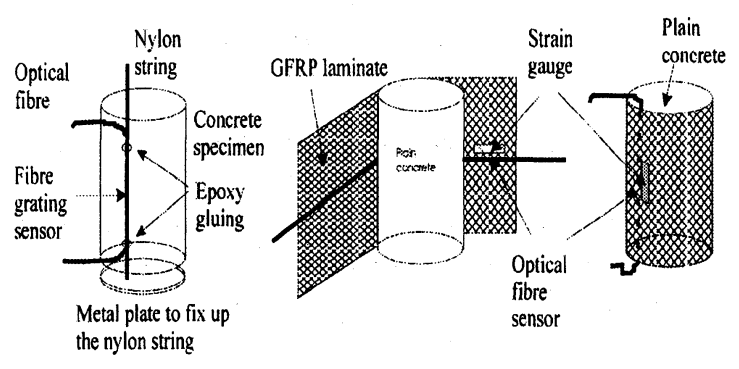

Fig.7. Schematic illustration of the FBG sensor embedded specimens. concrete specimen and at the interface between the concrete surface and GFRP laminate. The specimens were then compressed to $1 / 3$ of its ultimate compression load value for three repeated loading cycles. The test results of the FBG sensor compared with the surface bonded strain gauge are demonstrated in Fig.9.

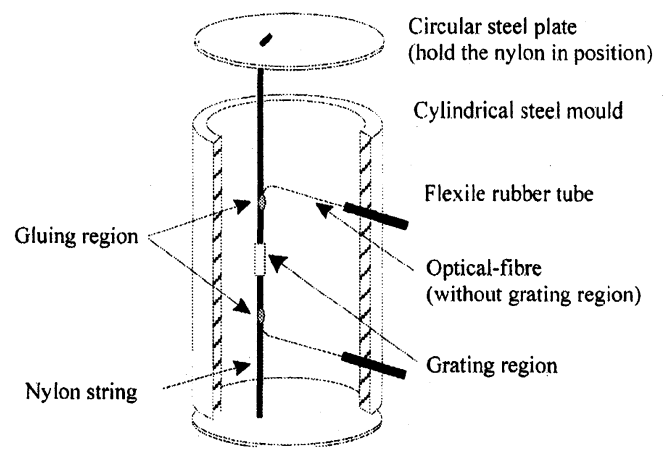

Fig.8. Schematic diagram for the installation set up of embedding FBG sensor into the concrete specimen.

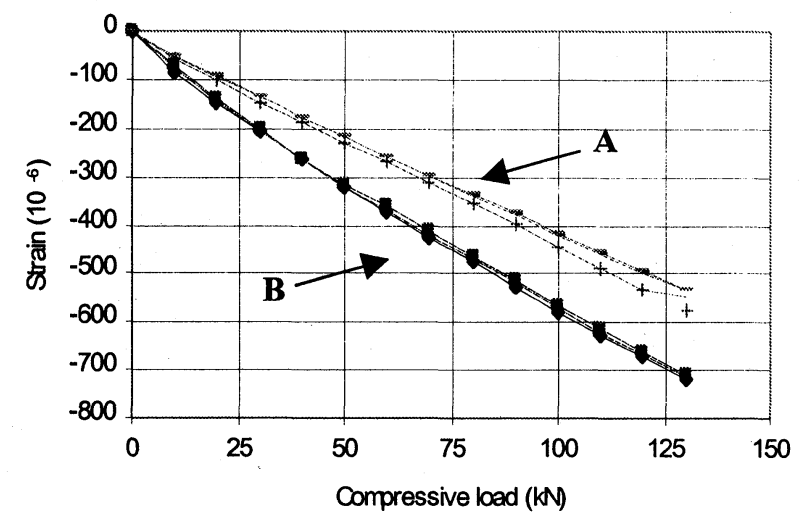

Fig.9. The experimental results of strain measured by using embedded FBG sensor (solid line) and surface bonded strain gauge (dot line). Results A: confined specimen with GFRP wrapping; Results B: Plain concrete specimen.

\section{RESULTS AND DISCUSSION}

\subsection{Concrete Strengthening}

The test results of the cylindrical concrete specimens under compressive applied load with and without strengthening by wrapping glass fibre composites are shown in Fig.10. The average ultimate compressive loads obtained from the tests are $390 \mathrm{kN}$ for plain concrete specimen and $415 \mathrm{kN}, 430 \mathrm{kN}$ and $445 \mathrm{kN}$ for the concrete specimens with 1,2 and 3 GFRP wrapping layers, respectively. Maximum strain was measured at the mid-height of the specimen and the GFRP was split off when further increasing the compression load beyond the peak value. The photograph of the plain and strengthened specimens after testing is shown in Fig.11. 


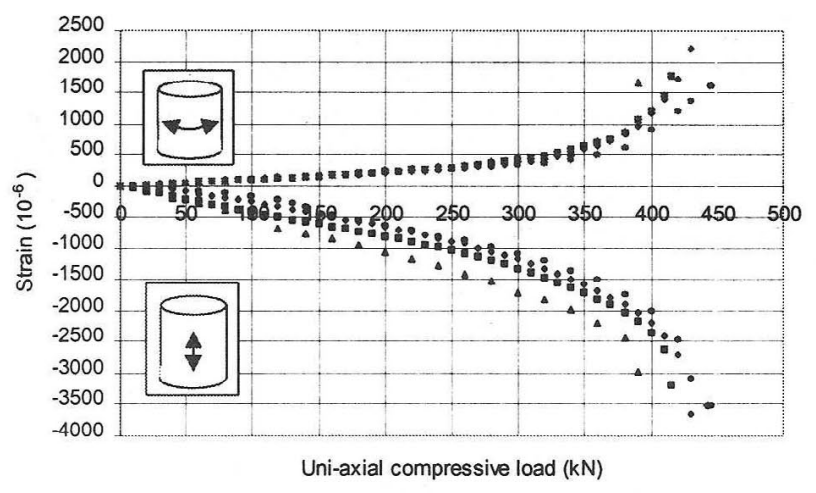

Fig.10. Experiment results of cylindrical concrete specimens with and without strengthening by using glass fibre composites. The triangular, rectangular, rhombic and circular spots represent the plain concrete specimen and confined specimens with 1, 2 and 3 layer(s) of GFRP composites, respectively.

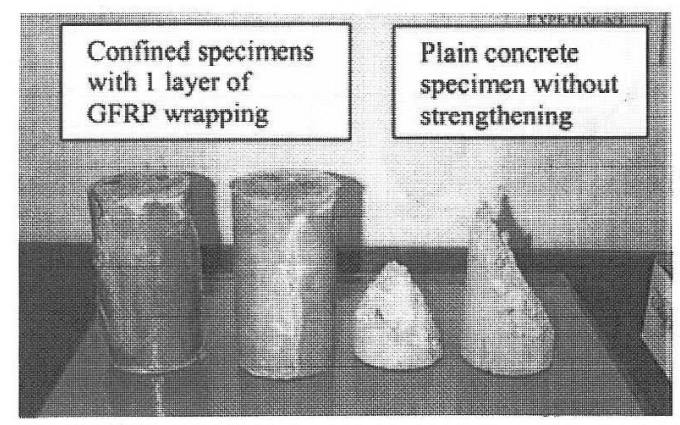

Fig.11. Photograph of the concrete specimen with and without strengthening by GFRP after testing.

The compression load-strain curves in Fig.10 show that the strength of the strengthened concrete specimen increases with an increase of the stiffness as well compared with plain concrete specimen. The load-strain relationship in lateral direction was found similarly and remains approximately unchanged in loading up to $75 \%$ of its ultimate load value. The load-strain relationships varied when further increasing the compression load. It was suspected that the micro cracking and the debonding between the aggregates and cement occurred beyond this limit.

The ultimate loads of the notched concrete specimen with and without strengthening by GFRP laminates were $330 \mathrm{kN}$ and $430 \mathrm{kN}$, respectively. The ultimate load of the strengthened-notched concrete specimen was increased by $11 \%$ compared to its un-notched status. The results from the experiments of notched concrete specimens with and without strengthening are shown in Fig.12. The strain measurement also indicated that the high stress concentration occurred in front of the notch tip. Cracking was initiated at the notch tip and extensively propagated toward both compression surfaces of the specimen.

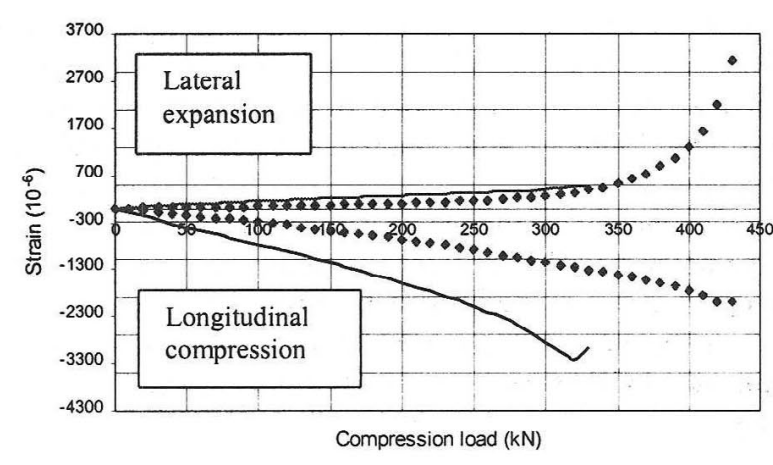

Fig.12. The strain reading from the external bonded strain gauge at the notch-tip of notched concrete specimen with (dot line) and without (solid line) strengthening.

\subsection{In-Situ Monitoring}

The strain reading from the sensor was well compared with the conventional strain gauge of the confined concrete specimen with 1 layer of GFRP laminate. The results of the experiment are illustrated in Fig.13. The compressive strain measured from the uni-axial compression tests gave the consistent reading between the FBG sensor and strain gauge when the compressive load was applied up to $70 \%$ of its ultimate load value. The readings are diverged when the applied load continuously increase. It is speculated that the confined cylindrical concrete specimens develop considerably more cracking than that for the un-confined samples, especially at the concrete surface which is inside the confined region.

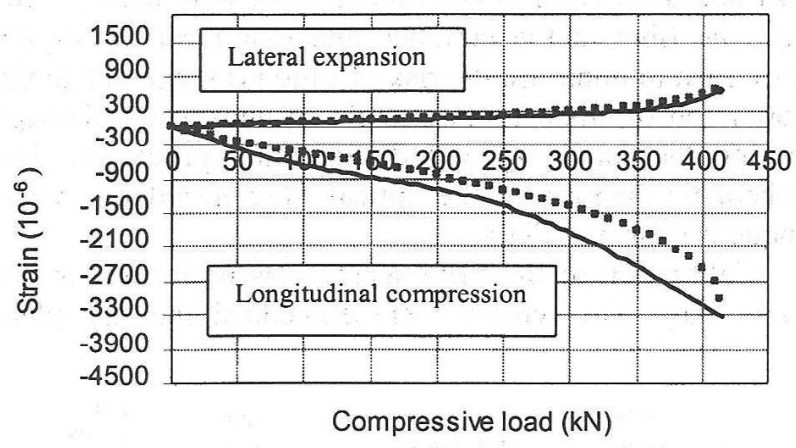

Fig.13. The strain measured by the FBG sensor at the interface between concrete and GFRP laminate and external bonded strain gauge of the confined concrete specimen with 1 layer GFRP wrapping (dot line: by strain gauge; solid line: by FBG sensor).

For the notched concrete specimen, the strain measured from FBG sensor was greater than that for the external bonded strain gauge at ultimate load condition. It was revealed that the stress was still concentrated inside 
the concrete and in front of the notch-tip. The properties change in this region cannot be measured via externally bonded strain gauge. The results of the strain measured using FBG sensor and strain gauge at the notch-tip are shown in Fig. 14.

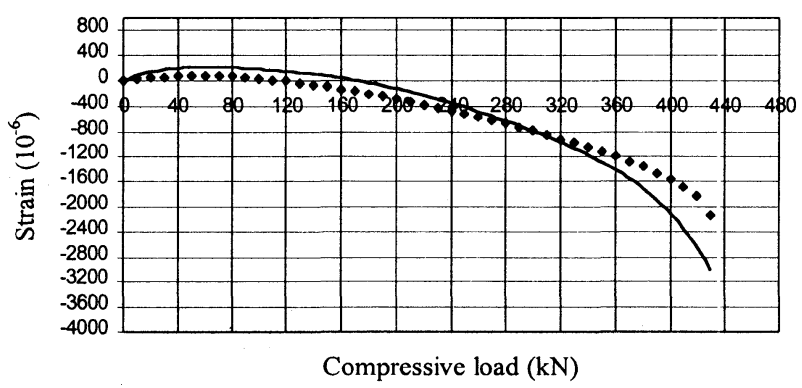

Fig.14. The strain measured at the notch-tip from the FBG sensor (solid line) and external bonded strain gauge (dot line) of notched concrete specimen.

\section{CONCLUSION}

Embedding Fibre-optic Bragg grating (FBG) sensor into the strengthened concrete structure presents their applicability in monitoring the interior mechanical behaviour of the structure under the applied load. The test results indicated that the use of glass fibre composites in strengthening the cylindrical concrete structure provided a considerable increase in its ultimate compressive load capacity. Also, no slipping and de-bonding failures were found when ultimate load was reached.

The associated instrumentation system using FBG sensor for the monitoring of the concrete structure, which is strengthened by the glass fibre composites gives a good comparable result with the externally bonded strain gauge. By using this technique, it enables to manage the structural-health condition and provide the accurate strain profile and history of the structure after strengthening.

In the future, more efforts are still needed in cooperating both strengthening and structural selfmonitoring techniques using glassfibre composites and FBG sensor, respectively in order to develop fast, economic and safe means in concrete rehabilitation applications.
Acknowledgements - This work was supported by the Hong Kong Polytechnic University Research Grant.

\section{REFERENCES}

1. H. Sameer and S. H. Ahmad, J. Materials and Structures, 30 (1997) 418.

2. J. P. Busel and K. Lindsay, J. Composites Design and Application, Jan/Feb (1997) 14.

3. Composites News, XXsys Technologies, Inc. San Diego, 9 (1994).

4. H. N. Garden, L. C. Hollaway and A. M. Thorne, J. Materials and Structures, 31 (1998) 247.

5. L. Cercone and F. Policelli, Construction Specifier Magazine on Retrofitting Corroded Bridge with Composites, XXsys Technologies, Inc. San Diego (1997).

6. S. Hamoush and S. H. Ahmad, J. Materials and Structures, 30 (1997) 418.

7. D. J. Oehlers, M. S. Mohamed Ali and W. Luo, J. Structural Engineering, March (1998) 224.

8. B. Taljsten, J. Materials in Civil Engineering, Nov (1997) 206.

9. A. Yokoyama and K. Nishiyabu, Proc. ACCM-1, 1 (1998) 103.

10. T. Asakura, Y. Kojima, T. Takahashi and H. Yoshizawa, Proc. ACCM-1, Vol 1 (1998) 106.

11. C. S. Hong, C. Y. Ryu and D. I. Park, Proc. ACCM-1, 2 (1998) 625

12. K. T. Lau, L. M. Zhou and C. H. Woo, Proc. ACCM-1, 2 (1998) 627.

13. E. Udd, Fibre Optic Smart Structures, John Wiley \& Sons, Inc. (1995) P23.

14. M. Shahawy and T. Beitelman, Proc. ASCE Structures Congress XIII, (1995) 796.

15. M. Aroockiasamy and R. Sowrirajan, J. Compsoites, 27B (1996) 217.

16. C. Doyle, A. Martin. T. Liu, M. Wu, S. Hayes, P. A. Crosby, G. R. Powell, D. Brooks and G. F. Fernando, J. Smart Materials, 7 (1998) 145.

17. U. Meier and H. Kaiser, Proc. ASCE Specialty Conference on Advanced Composites Materials in Civil Engineering Structures, New York (1991) 224.

18. A. A. Mufti and M. A. Erki, Advanced Composite Materials with Applications to Bridges, Canadian Society for Civil Engineering, Montreal (1991).

19. V. E. Saouma, D. Z. Anderson, K. Ostrander, B. Lee and V. Slowik, J. Materials and Structures, 31 (1998) 259.

20. B. Culshaw and J. Dakin: Optical Fibre Sensors Volume Three, Components and Subsystems, Artech House, Inc. Norwood (1996). 